\title{
Communication
}

\section{Distance Measurement of a Non-covalently Bound Y@C Pair with Double Electron Electron Resonance Spectroscopy}

Guzman Gil-Ramirez, Anokhi Shah, Hassane El Mkami, Kyriakos Porfyrakis, G.

Andrew D. Briggs, John J. L. Morton, Harry L. Anderson, and Janet E. Lovett

J. Am. Chem. Soc., Just Accepted Manuscript • DOI: 10.1021/jacs.8b03889 • Publication Date (Web): 02 Jun 2018

Downloaded from http://pubs.acs.org on June 6, 2018

\section{Just Accepted}

"Just Accepted" manuscripts have been peer-reviewed and accepted for publication. They are posted online prior to technical editing, formatting for publication and author proofing. The American Chemical Society provides "Just Accepted" as a service to the research community to expedite the dissemination of scientific material as soon as possible after acceptance. "Just Accepted" manuscripts appear in full in PDF format accompanied by an HTML abstract. "Just Accepted" manuscripts have been fully peer reviewed, but should not be considered the official version of record. They are citable by the Digital Object Identifier (DOI®). "Just Accepted" is an optional service offered to authors. Therefore, the "Just Accepted" Web site may not include all articles that will be published in the journal. After a manuscript is technically edited and formatted, it will be removed from the "Just Accepted" Web site and published as an ASAP article. Note that technical editing may introduce minor changes to the manuscript text and/or graphics which could affect content, and all legal disclaimers and ethical guidelines that apply to the journal pertain. ACS cannot be held responsible for errors or consequences arising from the use of information contained in these "Just Accepted" manuscripts. 
Spin-active endohedral fullerenes such as $\mathrm{N} @ \mathrm{C}_{60}$ and $\mathrm{Y} @ \mathrm{C}_{82}$ possess exceptionally long phase memory times $\left(T_{\mathrm{m}}\right)$, which characterize the lifetime of spin coherence: as long as $80 \mu \mathrm{s}$ at room temperature and over $200 \mu$ s at low temperature $(<200 \mathrm{~K}) .{ }^{1}$ These long times have led to their study as potential molecular electron spin quantum bits (qubits), using them to store and potentially process quantum information, ${ }^{2}$ or as spin labels. ${ }^{3}$ Both applications require the ability to accurately position such endohedral fullerenes with respect to each other to achieve a well-defined spin-spin coupling, or within some larger molecule to serve as a label. A promising approach is to use non-covalent interactions and generate receptors that can bind endohedral fullerenes and place them at fixed distances. ${ }^{4}$ Such an approach offers the flexibility to be applied to a variety of fullerene species regardless of their chemical stability, unlike covalent attachment chemistry. ${ }^{2 \mathrm{e}, 5}$ Non-covalent binding causes less disruption of the environment of the spin and therefore maintains the long coherence time. ${ }^{5}$ Porphyrins are well-known to interact favorably with fullerenes through a combination of $\pi-\pi$ and van der Waals interactions. ${ }^{6}$ These interactions have been exploited in the design of porphyrinbased receptors incorporating two or more porphyrins. ${ }^{7,8}$

Here we report the synthesis of a porphyrin-based receptor for fullerenes, containing two independent binding sites within a rigid framework (Figure 1). Receptor 1 binds two spin-active fullerenes $\left(\mathrm{Y} @ \mathrm{C}_{82}\right)$ placing them at a distance of $5.0 \mathrm{~nm}$ as shown by molecular modeling. We demonstrate that this distance is consistent

with the dipole-dipole coupling of two bound $\mathrm{Y} @ \mathrm{C}_{82}$ measured by the pulsed EPR technique of double electron electron resonance DEER, also known as PELDOR, ${ }^{9}$ which measures the dipolar coupling between proximal spins as a modulation on the detected spin-echo intensity. Since the anisotropy in both the $g$ tensor and hyperfine coupling tensor is small for the $\mathrm{Y} @ \mathrm{C}_{82}$, distances may be extracted using methods developed for nitroxide spin labels, assuming no significant orientation selection is present. ${ }^{10}$ This analysis assumes the excitation bandwidth of the pulses exceeds the dipole-dipole coupling frequency - a condition that will be met with the predicted $5.0 \mathrm{~nm}$ distance separation and available pulse lengths. ${ }^{10 b, 11}$

In designing a rigid porphyrin-based host that can encapsulate fullerenes we decided to construct a receptor with two independent binding sites connected through a rigid linker. We previously reported a receptor that utilizes a cyclic Zn-porphyrin trimer in which three porphyrins are preorganized to chelate to the same fullerene guest, displaying high affinity and selectivity for the larger fullerenes $\left(K_{\mathrm{a}}>10^{9} \mathrm{M}^{-1}\right.$ for $\mathrm{La}_{0} \mathrm{C}_{82}$ in toluene) ${ }^{8 \mathrm{a}} \mathrm{Zn}$ porphyrins, can be expected to produce purely non-covalent interactions between the highly polarizable fullerenes and the metalloporphyrins. ${ }^{12}$ In contrast, other metals such as $\mathrm{Co}$ (II) or Rh(III) produce strong polarized complexes that might affect the spin environment of the endohedral fullerene. ${ }^{6 c}$

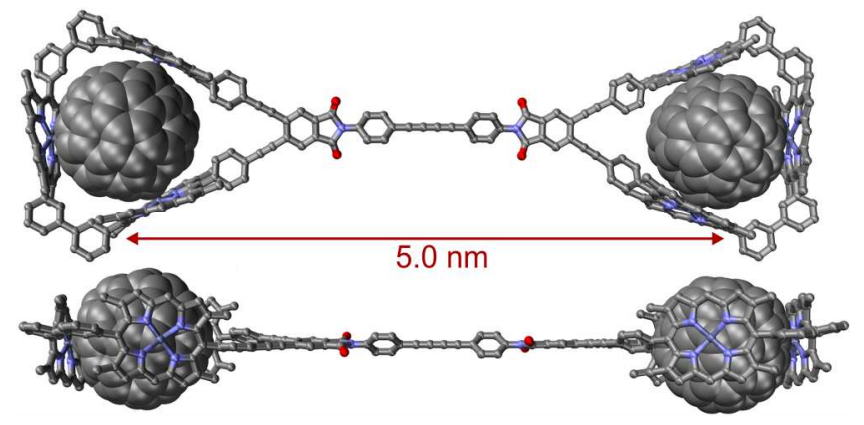

Figure 1. MM+ molecular model of the complex $\left(\mathrm{Y} @ \mathrm{C}_{82}\right)_{2} \cdot \mathbf{1}$ formed by the cyclic porphyrin trimer receptor $\mathbf{1}$ and $\mathrm{Y} @ \mathrm{C}_{82}$. The red line highlights the distance between the centroids of the two $\mathrm{Y} @ \mathrm{C}_{82}$ fullerenes. 
Scheme 1. Synthesis of the Two Sites Receptor 1.

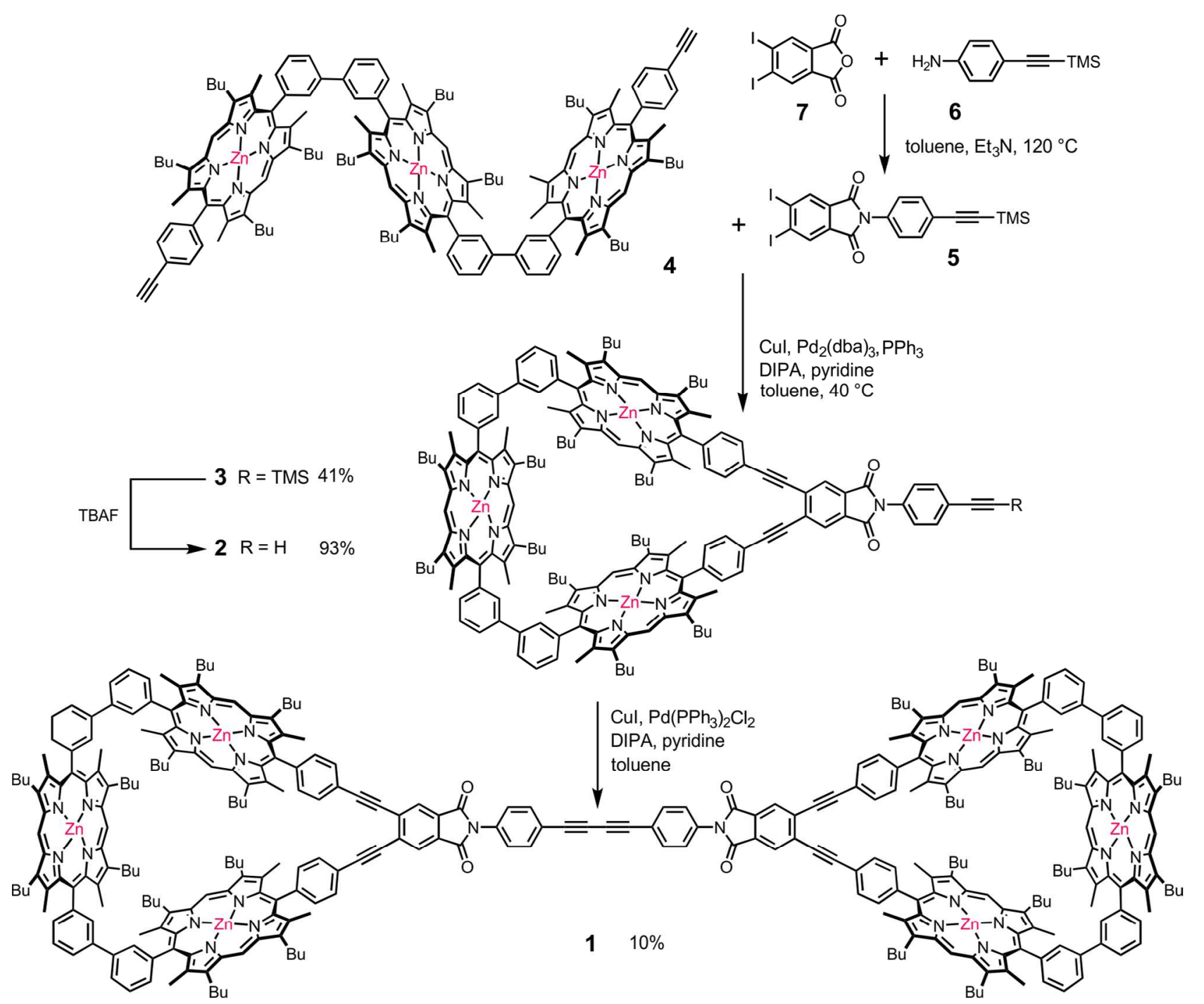

As a proof of concept, the simplest system of coupling two endohedral fullerene spins was investigated. Hence, the requirement for incorporation of two fullerene binding hosts, inspired by our previous fullerene host, connected by a rigid linker led to the design of receptor $\mathbf{1}$ (Scheme 1). The spacer connecting both porphyrin trimers was chosen to give a rigid structure, which could favor alignment in a suitable matrix, such as a nematic liquid crystal. The design of $\mathbf{1}$ features a central butadiyne link so that efficient alkyne homocoupling could be used in the final step to connect both binding sites (Scheme 1). $\mathrm{Y} @ \mathrm{C}_{82}$ was selected as the spin-active fullerene, as it has a single unpaired electron making the EPR data analysis easier. By using the endohedral fullerene $\mathrm{Y} @ \mathrm{C}_{82}$, receptor $\mathbf{1}$ is effectively "spin labeled" with the $S=1 / 2 \mathrm{Y}$ atoms. Dipole-dipole coupling is thus expected between the $\mathrm{Y} @ \mathrm{C}_{82}$ with a strength that follows the inverse cube of the interspin separation, and is also a function of the angle the interspin vector makes with the applied field..$^{9-11,13}$

Molecular mechanics calculations, performed by employing a $\mathrm{MM}+$ force field using the HyperChem8 software (see Supporting Information) showed that the distance between the $\mathrm{C}_{82}$ centroids of bound fullerenes within receptor $\mathbf{1}$ is $5.0 \mathrm{~nm}$ (Figure 1). Porphyrin receptor 1 was synthesized by palladium-catalyzed homocoupling of cyclic porphyrin trimer 2 (Scheme 1). The cyclic porphyrin trimer 3 was prepared by Sonogashira coupling of the alkyne-terminated linear porphyrin trimer $4^{\text {sa }}$ and the 4,5-

diiodophthalimide $\mathbf{5}$, followed by removal of the TMS group to give cyclic porphyrin trimer $\mathbf{2}$. Compound $\mathbf{5}$ was obtained by condensation of 4,5-diiodophthalimide anhydride $\mathbf{6}^{14}$ with $p$-(2trimethylsilylethynyl)aniline $7 .{ }^{15}$

The ${ }^{1} \mathrm{H}$ NMR spectrum of the cyclic porphyrin trimer 1 confirms its $C_{2 \mathrm{v}}$ symmetry. Its purity and identity were established by ${ }^{1} \mathrm{H}$ NMR, ${ }^{13} \mathrm{C}$ NMR, ${ }^{1} \mathrm{H}^{-1} \mathrm{H}$ NOESY, GPC, MALDI-TOF MS, and UV-vis spectroscopy (see Supporting Information).

The rigid phthalimide-containing linker between the two independent binding sites should generate a system capable of binding fullerenes at a fixed distance in a non-cooperative manner with high affinity. UV/vis/NIR titrations provided insight into the self-assembly process. Changes in the absorption spectrum of receptor $\mathbf{1}$ as a function of increased concentration of $\mathrm{Y} @ \mathrm{C}_{82}$ are plotted in Figure 2. Upon addition of $\mathrm{Y} @ \mathrm{C}_{82}$ to a solution of $\mathbf{1}$ in toluene, the formation of a complex with a red-shifted Soret band was detected. The band maximum shifted from $423 \mathrm{~nm}$ to 427 $\mathrm{nm}$.

Titration of $\mathbf{1}$ with $\mathrm{Y} @ \mathrm{C}_{82}$ gave an abrupt end-point at two equivalents of $\mathrm{Y} @ \mathrm{C}_{82}$, thus demonstrating the formation of the $\left(\mathrm{Y} @ \mathrm{C}_{82}\right)_{2} \bullet \mathbf{1}$ complex but the binding curve was too square to provide a measure of the binding constants (see Supporting Information). A modified Job's plot obtained using the continuous variation method ${ }^{16}$ displayed a maximum at molar fraction $X_{\mathrm{A}}=$ 
0.33 (Figure 2b) confirming that the $1: \mathrm{Y} @ \mathrm{C}_{82}$ stoichiometry is $c a$. 1:2.
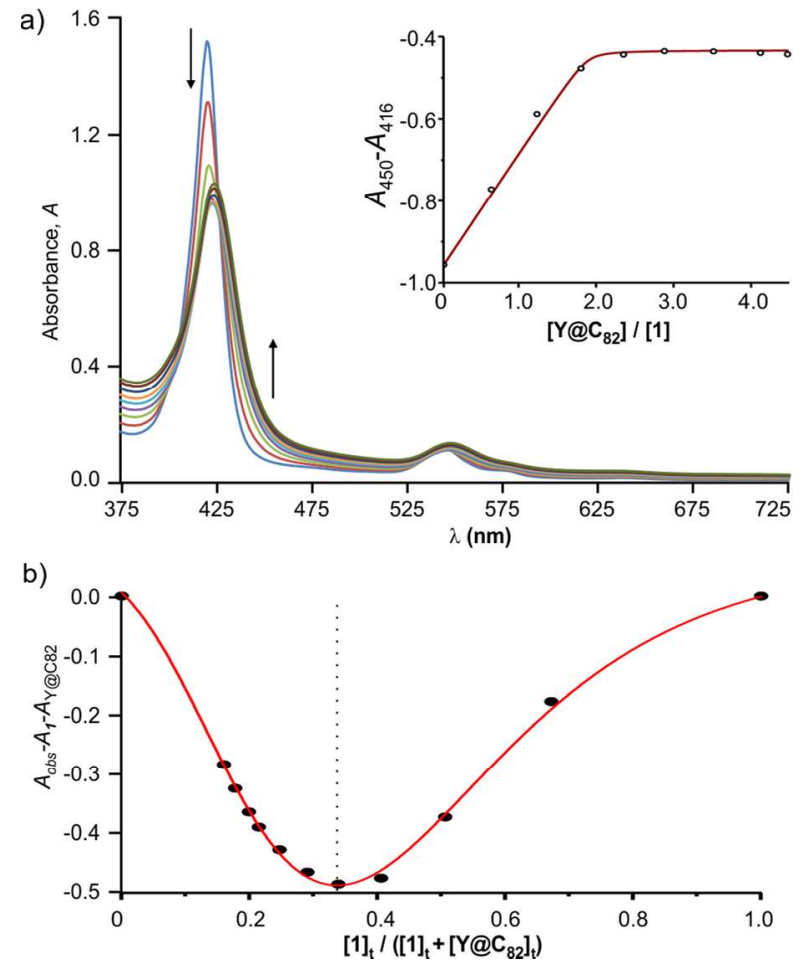

Figure 2. (a) UV/vis titration of $\mathrm{Y} @ \mathrm{C}_{82}$ into $\mathbf{1}(c=0.47 \mu \mathrm{M}$, toluene, $298 \mathrm{~K}$ ). Arrows indicate the spectral change with increasing $\mathrm{Y} @ \mathrm{C}_{82}$ concentration. Insert shows the binding curve derived from these spectra. (b) Modified Job's plot for the complexation of 1 and $\mathrm{Y} @ \mathrm{C}_{82}$. [1 $]_{\mathrm{t}}=$ total concentration of host; $\left[\mathrm{Y} @ \mathrm{C}_{82}\right]_{\mathrm{t}}=$ total concentration of guest; $A_{\mathrm{obs}}=$ Absorbance observed at 423 $\mathrm{nm} ; A_{1}=$ Compound $\mathbf{1}$ absorbance at $423 \mathrm{~nm} ; A_{\mathrm{Y} @ \mathrm{C} 82}=\mathrm{Y} @ \mathrm{C}_{82}$ absorbance at $423 \mathrm{~nm}$.

In order to prepare an optimal sample for measuring dipoledipole coupling between the bound $\mathrm{Y} @ \mathrm{C}_{82}$ by DEER, the system was modeled considering three criteria: a) larger guest to host ratios increase the double-filled receptor species over single-filled or empty receptor species; b) lower concentrations of $\mathbf{1}$ decrease spin-spin relaxation effects; c) DEER will work optimally with approximately complete binding of available $\mathrm{Y} @ \mathrm{C}_{82}$ and complete filling of the receptor sites. From simulations obtained using the modeling program HySS 2009 it was found that $[\mathbf{1}]=10^{-6} \mathrm{M}$ offers a good compromise between keeping the concentration low, to minimize spin-spin relaxation effects, while still affording 96 $\%$ of the double bound species $\left(\mathrm{Y} @ \mathrm{C}_{82}\right)_{2} \cdot \mathbf{1}$ when just two equivalents of $\mathrm{Y} @ \mathrm{C}_{82}$ are present (see Supporting Information). ${ }^{17}$

A sample containing $1 \mu \mathrm{M}\left(\mathrm{Y} @ \mathrm{C}_{82}\right)_{2} \cdot \mathbf{1}$ prepared in deuterated toluene was used for all pulsed EPR measurements on the frozen solution. Fullerene $\mathrm{Y} @ \mathrm{C}_{82}$ was used as a mixture of isomers. ${ }^{18}$ Deuterated toluene was used since it has previously been shown to significantly increase the $T_{\mathrm{m}}$ time of $\mathrm{Y} @ \mathrm{C}_{82}{ }^{1 \mathrm{~b}}$ We found that the $T_{\mathrm{m}}$ of the bound $\mathrm{Y} @ \mathrm{C}_{82}$ is of the order of $2 \mu \mathrm{s}$ in the $20-60 \mathrm{~K}$ temperature range, and that no signal from unbound $\mathrm{Y} @ \mathrm{C}_{82}$ is detectable (see Supporting Information for details). Furthermore, the $T_{\mathrm{m}}$ remains about the same in the temperature range $20-60 \mathrm{~K}$, whereas the $T_{\mathrm{m}}$ of $\mathrm{Y} @ \mathrm{C}_{82}$ in deuterated toluene in the same temperature range varies from 20 to $90 \mu \mathrm{s} .{ }^{1 \mathrm{~d}}$ These changes indicate complete binding. The dramatic reduction in $T_{\mathrm{m}}$ upon binding the fullerene is likely due to the spectral diffusion with ${ }^{1} \mathrm{H}$ nuclear spins in the porphyrin cage, and this is consistent with the meas-

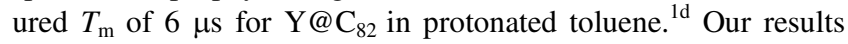

highlight the importance of removing all protons and other sources that may decrease the $T_{\mathrm{m}}$ of the spin - this could be explored using a deuterated form of $\mathbf{1}$, however the nitrogen nuclear spin of the porphyrin as well as spectral and /or instantaneous diffusions processes driven by the dipole-dipole interactions could nevertheless influence $T_{\mathrm{m}}$.
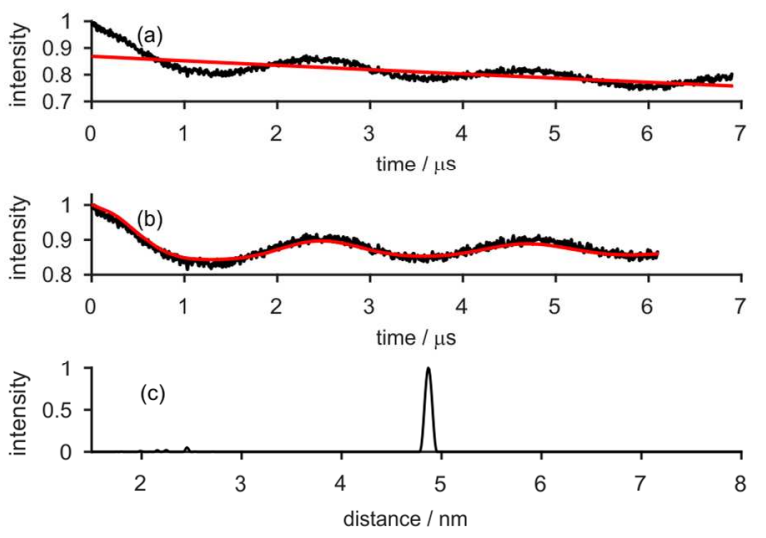

Figure 3. DEER results obtained at Q-band for $\left(\mathrm{Y} @ \mathrm{C}_{82}\right)_{2} \bullet \mathbf{1}$ complex: (a) normalized raw data; (b) post-background subtraction with red line showing the fit obtained using DeerAnalysis 2016 with Tikhonov Regularization parameter 10, see Supporting Information for further information; ${ }^{10 \mathrm{~b}}$ (c) the resulting distance distribution over the fitting range 1.5 to $8.0 \mathrm{~nm}$.

DEER was used to directly measure the dipole-dipole coupling between the electron spin centers to investigate whether $\left(\mathrm{Y} @ \mathrm{C}_{82}\right)_{2} \bullet \mathbf{1}$ has the structure predicted from molecular modeling and confirm two-site binding. At X-band frequencies $(9-10 \mathrm{GHz})$ the observed dipolar frequency matches the oscillation frequency present in the three-pulse electron spin echo envelope modulation (ESEEM) experiment (see Supporting Information) and we could not be certain that this signal was not being measured by DEER. However, in contrast to the dipolar coupling frequency, the nuclear spin frequencies depend strongly on the magnetic field and on the operating microwave frequency. We therefore measured DEER at Q-band (34 GHz), as well as X-band, to show that the DEER modulations are due to field independent dipole-dipole coupling. The results are shown in Figure 3 and the main distance peak has a mean of $4.87 \mathrm{~nm}$ and a standard deviation of $0.03 \mathrm{~nm}$. The mean distance corresponds very well with the molecular modeling centroid-centroid distance despite the asymmetry of the $\mathrm{C}_{82}$ cage and presumed spin-delocalization onto the fullerene (Figure 1). The modulations on the time traces are indicative of narrow distance distributions. The restriction on the length of the DEER data that was imposed by the $T_{\mathrm{m}}$ precludes an accurate measurement of the width of the distribution and the $0.03 \mathrm{~nm}$ presented here is an upper limit (see Supporting Information). The narrow distance distributions and the near coincidence of the experimentally obtained distance with the centroid-centroid distance from the molecular modeling for the asymmetric $\mathrm{Y}_{0} \mathrm{C}_{82}$ suggest that the fullerene is either rapidly tumbling within the porphyrin trimers in the frozen solution, or is localized with respect to the porphyrin trimers. Given that the molecular rotations would need to be on a timescale that allows averaging of the dipole-dipole coupling but not of the hyperfine anisotropy, we conclude that the $\mathrm{Y} @ \mathrm{C}_{82}$ spin is fixed in place. We note that the modulation depth of the DEER signal was smaller than expected given the broad level of excitation of the absorption signal, and that all other indicators point to near complete double filling of receptor $\mathbf{1}$. The dipole-dipole coupling that DEER measures relies on interspin distances and the orientation of the spin-spin vector with respect 
to the magnetic field. ${ }^{13}$ Orientation-selection could be responsible for the decrease in modulation depth and the apparent small distribution in distances. However, we could not detect any appreciable orientation-selection at Q-band (see Supporting Information). The, as yet, unexplained observation of reduced modulation depth, may be due to pulse overlap from the pump and observer frequencies for DEER in the narrow $\mathrm{Y} @ \mathrm{C}_{82}$ absorption spectrum, or other diffusion mechanisms.

In conclusion, we have synthesized a receptor for fullerenes containing two independent binding sites connected by a rigid linker. We have prepared a double-filled receptor containing two $\mathrm{Y} @ \mathrm{C}_{82}$ fullerenes. The spin systems are separated by a distance of $5.0 \mathrm{~nm}$ according to molecular modeling. We have used DEER at $\mathrm{X}$ - and Q-band to show that the dipolar coupling strength matches that distance very well. To our knowledge, this is the first demonstration of DEER with any endohedral fullerene. The narrow distance distribution indicates that $\mathbf{1}$ could be useful for applications requiring spin entanglement. The short phase memory time of the electron spin observed in the bound $\mathrm{Y} @ \mathrm{C}_{82}$ may be significantly reduced by removing the protons or exchanging them with deuterons. The supramolecular receptor 1 (Scheme 1) presented here opens the way for future work on a bottom-up approach to arrays of coupled endohedral fullerene spins.

\section{ASSOCIATED CONTENT}

\section{Supporting Information}

The Supporting Information is available free of charge on the ACS Publications Website at DOI: Experimental methods and characterization data, including mass, UV-vis-NIR, NMR and EPR spectra. EPR data underpinning this work is available at DOI: 10.17630/987ef725-e94f-4f90-b109-5e338936b1bc

\section{AUTHOR INFORMATION}

\section{Corresponding Author \\ ggilramirez@lincoln.ac.uk}

\section{Notes}

The authors declare no competing financial interests.

\section{ACKNOWLEDGMENT}

We thank the EPSRC (EP/I035536/1; EP/J015067/1), The Royal Society (University Research Fellowship to JEL) and Wellcome Trust (099149/Z/12/Z) for funding and the EPSRC UK National Mass Spectrometry Facility at Swansea University for mass spectra. We also thank Dr. Graham Smith and Sapna Sinha for useful discussions.

\section{REFERENCES}

(1) (a) Morton, J. J. L.; Tyryshkin, A. M.; Ardavan, A.; Porfyrakis, K.; Lyon, S. A.; Briggs, G. A. D., J. Chem. Phys. 2006, 124, 014508. (b) Brown, R. M.; Ito, Y.; Warner, J. H.; Ardavan, A.; Shinohara, H.; Briggs, G. A. D.; Morton, J. J. L., Phys. Rev. B: Condens. Matter 2010, 82, 033410. (c) Morton, J. J. L.; Tyryshkin, A. M.; Ardavan, A.; Porfyrakis, K.; Lyon, S. A.; Briggs, G. A. D., Phys. Rev. B: Condens. Matter 2007, 76, 085418. (d) Brown, R. M.; Tyryshkin, A. M.; Porfyrakis, K.; Gauger, E. M.; Lovett, B. W.; Ardavan, A.; Lyon, S. A.; Briggs, G. A. D.; Morton, J. J. L., Phys. Rev. Lett. 2011, 106, 110504.

(2) (a) Harneit, W., Phys. Rev. A: At. Mol. Opt. Phys. 2002, 65, 032322. (b) Benjamin, S. C.; Ardavan, A.; Briggs, G. A. D.; Britz, D. A.; Gunlycke, D.; Jefferson, J.; Jones, M. A. G.; Leigh, D. F.; Lovett, B. W.; Khlobystov, A. N.; Lyon, S. A.; Morton, J. J. L.; Porfyrakis, K.; Sambrook, M. R.; Tyryshkin, A. M., J. Phys.: Condens. Matter 2006, 18, S867. (c) Wesenberg, J. H.; Ardavan, A.; Briggs, G. A. D.; Morton, J. J.
L.; Schoelkopf, R. J.; Schuster, D. I.; Mølmer, K., Phys. Rev. Lett. 2009, 103, 070502. (d) Yang, W. L.; Xu, Z. Y.; Wei, H.; Feng, M.; Suter, D., Phys. Rev. A: At. Mol. Opt. Phys. 2010, 81, 032303. (e) Plant, S. R.; Jevric, M.; Morton, J. J. L.; Ardavan, A.; Khlobystov, A. N.; Briggs, G. A. D.; Porfyrakis, K., Chem. Sci. 2013, 4, 2971-2975. (f) Ardavan, A.; Bowen, A. M.; Fernandez, A.; Fielding, A. J.; Kaminski, D.; Moro, F.; Muryn, C. A.; Wise, M. D.; Ruggi, A.; McInnes, E. J. L.; Severin, K.; Timco, G. A.; Timmel, C. R.; Tuna, F.; Whitehead, G. F. S.; Winpenny, R. E. P., Npj Quantum Information 2015, 1, 15012.

(3) (a) Zhou, S.; Yamamoto, M.; Briggs, G. A. D.; Imahori, H.; Porfyrakis, K., J. Am. Chem. Soc. 2016, 138, 1313-1319. (b) Liu, G.; Khlobystov, A. N.; Charalambidis, G.; Coutsolelos, A. G.; Briggs, G. A. D.; Porfyrakis, K., J. Am. Chem. Soc. 2012, 134, 1938-1941.

(4) (a) Boulon, M. E.; Fernandez, A.; Moreno Pineda, E.; Chilton, N. F.; Timco, G.; Fielding, A. J.; Winpenny, R. E. P., Angew. Chem. Int. Ed. 2017, 56, 3876-3879. (b) Ferrando-Soria, J.; Magee, S. A.; Chiesa, A.; Carretta, S.; Santini, P.; Vitorica-Yrezabal, I. J.; Tuna, F.; Whitehead, G. F. S.; Sproules, S.; Lancaster, K. M.; Barra, A.-L.; Timco, G. A.; McInnes, E. J. L.; Winpenny, R. E. P., Chem 2016, 1, 727-752. (c) Yazaki, K.; Akita, M.; Prusty, S.; Chand, D. K.; Kikuchi, T.; Sato, H.; Yoshizawa, M., Nat. Commun. 2017, 8, 15914.

(5) Farrington, B. J.; Jevric, M.; Rance, G. A.; Ardavan, A.; Khlobystov, A. N.; Briggs, G. A. D.; Porfyrakis, K., Angew. Chem. Int. Ed. 2012, $51,3587-3590$.

(6) (a) Garcia-Simon, C.; Costas, M.; Ribas, X., Chem. Soc. Rev. 2016, 45, 40-62. (b) Boyd, P. D. W.; Reed, C. A., Acc. Chem. Res. 2005, 38, 235-242. (c) Tashiro, K.; Aida, T., Chem. Soc. Rev. 2007, 36, 189-197.

(7) (a) Hajjaj, F.; Tashiro, K.; Nikawa, H.; Mizorogi, N.; Akasaka, T.; Nagase, S.; Furukawa, K.; Kato, T.; Aida, T., J. Am. Chem. Soc. 2011, 133, 9290-9292. (b) Nobukuni, H.; Shimazaki, Y.; Tani, F.; Naruta, Y., Angew. Chem. Int. Ed. 2007, 46, 8975-8978. (c) Hernández-Eguía, L. P.; Escudero-Adán, E. C.; Pinzón, J. R.; Echegoyen, L.; Ballester, P., J. Org Chem. 2011, 76, 3258-3265. (d) Durot, S.; Taesch, J.; Heitz, V., Chem. Rev. 2014, 114, 8542-8578. (e) Moreira, L.; Calbo, J.; Aragó, J.; Illescas, B. M.; Nierengarten, I.; Delavaux-Nicot, B.; Ortí, E.; Martín, N.; Nierengarten, J.-F., J. Am. Chem. Soc. 2016, 138, 15359-15367.

(8) For complexes using three or more porphyrins to bind fullerenes see: (a) Gil-Ramírez, G.; Karlen, S. D.; Shundo, A.; Porfyrakis, K.; Ito, Y.; Briggs, G. A. D.; Morton, J. J. L.; Anderson, H. L., Org. Lett. 2010, 12, 3544-3547. (b) Song, J.; Aratani, N.; Shinokubo, H.; Osuka, A., J. Am. Chem. Soc. 2010, 132, 16356-16357. (c) Mulholland, A. R.; Woodward, C. P.; Langford, S. J., Chem. Commun. 2011, 47, 1494-1496. (d) Zhu, B.; Chen, H.; Lin, W.; Ye, Y.; Wu, J.; Li, S., J. Am. Chem. Soc. 2014, 136, 15126-15129. (e) Fang, X.; Zhu, Y.-Z.; Zheng, J.-Y., J. Org. Chem. 2014, 79, 1184-1191. (f) Yu, C.; Long, H.; Jin, Y.; Zhang, W., Org. Lett. 2016, 18, 2946-2949. (g) Fukui, N.; Kim, T.; Kim, D.; Osuka, A., J. Am. Chem. Soc. 2017, 139, 9075-9088. (h) To, C. T.; Chan, K. S., New J. Chem. 2018, 42, 7599-7602.

(9) (a) Milov, A. D., K. M. Salikhov, and M. D. Shirov., Fiz. Tverd. Tela. 1981, 23, 975-982. (b) Martin, R. E.; Pannier, M.; Diederich, F.; Gramlich, V.; Hubrich, M.; Spiess, H. W., Angew. Chem. Int. Ed. 1998, 37 2833-2837.

(10) (a) Jeschke, G., Annu. Rev. Phys. Chem. 2012, 63, 419-446. (b) Jeschke, G.; Chechik, V.; Ionita, P.; Godt, A.; Zimmermann, H.; Banham, J.; Timmel, C. R.; Hilger, D.; Jung, H., Appl. Magn. Reson. 2006, 30, $473-$ 498. (c) Borbat, P. and Freed, J., in Structural Information from SpinLabels and Intrinsic Paramagnetic Centers in the Biosciences. Structure and Bonding, ed. Harmer, J. and Timmel, C., Springer, Heidelberg, Germany, 2014; Vol. 152, pp 1-82.

(11) Banham, J. E.; Baker, C. M.; Ceola, S.; Day, I. J.; Grant, G. H.; Groenen, E. J. J.; Rodgers, C. T.; Jeschke, G.; Timmel, C. R., J. Magn. Res. 2008, 191 (2), 202-218.

(12) Kang, B.; Totten, R. K.; Weston, M. H.; Hupp, J. T.; Nguyen, S. T., Dalton Trans. 2012, 41, 12156-12162.

(13) Lovett, J. E.; Bowen, A. M.; Timmel, C. R.; Jones, M. W.; Dilworth, J. R.; Caprotti, D.; Bell, S. G.; Wong, L. L.; Harmer, J., PCCP 2009, 11, 6840-6848.

(14) Higgins, R. W.; Hilton, C. L.; Willard, M. L.; Francis, H. J., Jr., J. Org. Chem. 1951, 16, 1577-81.

(15) Ishizaki, M.; Hoshino, O., Tetrahedron 2000, 56, 8813-8819.

(16) Renny, J. S.; Tomasevich, L. L.; Tallmadge, E. H.; Collum, D. B., Angew. Chem. Int. Ed. 2013, 52, 11998-12013.

(17) HySS2009 is an updated version of the older version reported in: Alderighi, L.; Gans, P.; Ienco, A.; Peters, D.; Sabatini, A.; Vacca, A., Coord. Chem. Rev. 1999, 184, 311-318. 
(18) Bao, L.; Pan, C.; Slanina, Z.; Uhlik, F.; Akasaka, T.; Lu, X., Angew. Chem. Int. Ed. 2016, 55, 9234-9238.

1

2

3

4

5

6

7

8

9

10

11

12

13

14

15

16

17

18

19

20

21

22

23

24

25

26

27

28

29

30

31

32

33

34

35

36

37

38

39

40

41

42

43

44

45

46

47

48

49

50

51

52

53

54

55

56

57

58

59

60 
Authors are required to submit a graphic entry for the Table of Contents (TOC) that, in conjunction with the manuscript title, should give the reader a representative idea of one of the following: A key structure, reaction, equation, concept, or theorem, etc., that is discussed in the manuscript. Consult the journal's Instructions for Authors for TOC graphic specifications.

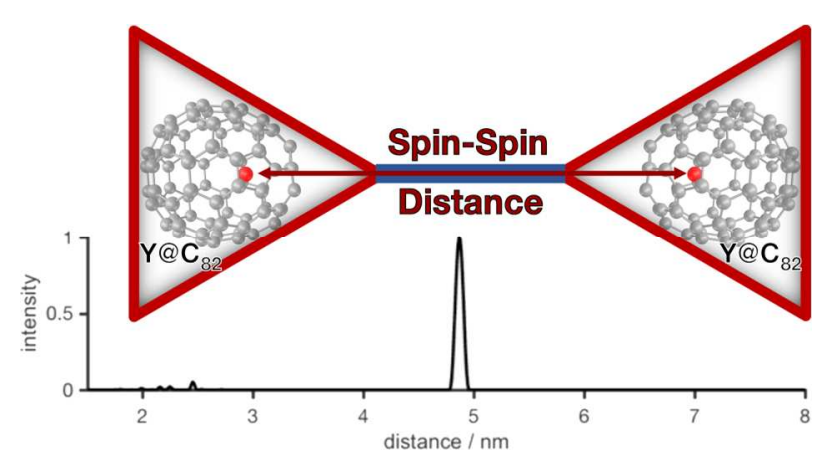

\section{NEW FIGURE ABOVE}

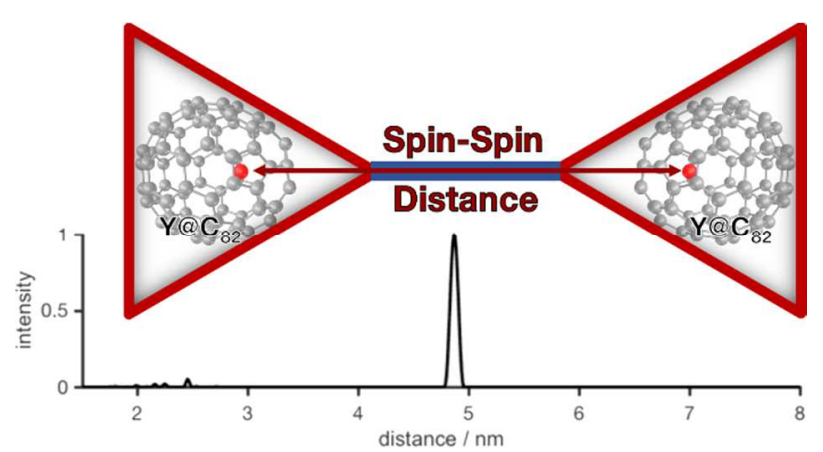

